\title{
Ocorrência e fatores de risco associados à infecção por lentivírus de pequenos ruminantes no Estado de Sergipe ${ }^{1}$
}

\author{
Huber Rizzo ${ }^{2 *}$, Taile K.S. Jesus ${ }^{3}$, Roberto S. Castro², José W. Pinheiro Júnior², \\ Lucas L.S. Soares ${ }^{4}$, Carla C.M. Oliveira ${ }^{4}$, Sérgio A. Nascimento ${ }^{5}$ e Tatiane R. Silva ${ }^{6}$
}

\begin{abstract}
Rizzo H., Jesus T.K.S., Castro R.S., Pinheiro Júnior J.W., Soares L.L.S., Oliveira C.C.M., Nascimento S.A. \& Silva T.R. 2018. [Occorrence and risk factors associated with small ruminant lentivirus infection in the State of Sergipe, Brazil.] Ocorrência e fatores de risco associados à infecção por lentivírus de pequenos ruminantes no Estado de Sergipe. Pesquisa Veterinária Brasileira 38(6):1043-1050. Departamento de Medicina Veterinária, Universidade Federal Rural de Pernambuco, Rua Dom Manoel de Medeiros s/n, Dois Irmãos, Recife, PE 52171-900, Brazil. E-mail: hubervet@gmail.com

The lentiviruses of small ruminants are infectious and multisystemic diseases caused by the Caprine Arthritis Encephalitis Virus (CAEV) and the Maedi-Visna Virus (MVV), and present the clinical forms: articular, mammary, respiratory and nervous. This work aimed to determine the occurrence and to evaluate the risk factors associated with lentivirus infection of small ruminants in the State of Sergipe, Brazil. Blood samples were collected from 1200 sheep and 675 goats from 60 and 41 farms respectively, located in 25 Sergipe municipalities from 2011 to 2014. The diagnosis of small ruminant lentiviruses (LVPR) was determined by the serological technique of Immunodiffusion in Gel Agar (IDGA) using the commercial kit of the brand Biovetech ${ }^{\circledR}$. Data from the variables associated with risk factors were obtained from questionnaires applied to the owners of the herds and analyzed statistically. Absolute and relative frequencies were determined by descriptive statistical analysis and risk factors by univariate analysis of the variables of interest by Pearson's Chi-square test and Fisher's exact test, when necessary. A logistic regression analysis was used, considering as a dependent variable for LVPR infection the reactive or non-reactive result observed in the IDGA. A seropositivity of 5.03\% (34/675) was observed in goats and $1.50 \%$ in sheep with $26.82 \%(11 / 41)$ and $28.33 \%$ (17/60) of the properties had at least one animal positive respectively. The analysis of the risk factors, no significant differences were observed for sheep, while for goats, herds above 100 animals grazing in common areas with other herds, at a distance $\leq 500$ meters between the properties, that adopt Biotechnological measures of reproduction and do not use sterile needles, are more susceptible to LVPR infection. Therefore, it's concluded there is presence of lentiviruses of small ruminants in sergipan herds, and even if at low frequencies it is necessary to implement prophylactic measures due to the possibility of expansion and development of goat breeding of the state and the high genetic standard of the Santa Inês breed.
\end{abstract}

INDEX TERMS: Risk factors, small ruminants, lentivirus infection, Sergipe, Caprine Arthritis Encephalitis Virus, goats, immunodiffusion, agar gel, Maedi-Visna, sheep, viroses.

\footnotetext{
${ }^{1}$ Recebido em 1 de abril de 2017.

Aceito para publicação em 12 de maio de 2017.

${ }^{2}$ Docente do Departamento de Medicina Veterinária (DMV), Universidade Federal Rural de Pernambuco (UFRPE), Rua Dom Manoel de Medeiros s/n, Dois Irmãos, Recife, PE 52171-900, Brasil. *Autor para correspondência: hubervet@gmail.com

${ }^{3}$ Discente do Programa de Pós-Graduação em Ciência Veterinária, Departamento de Medicina Veterinária (DMV), Universidade Federal Rural de Pernambuco (UFRPE), Rua Dom Manoel de Medeiros s/n, Dois Irmãos, Recife, PE 52171-900.
}

\footnotetext{
${ }^{4}$ Discente do Curso de Medicina Veterinária, Departamento de Medicina Veterinária (DMV), Universidade Federal Rural de Pernambuco (UFRPE), Rua Dom Manoel de Medeiros s/n, Dois Irmãos, Recife, PE 52171-900.

${ }^{5}$ Técnico do Laboratório de Virologia, Departamento de Medicina Veterinária (DMV), Universidade Federal Rural de Pernambuco (UFRPE) Rua Dom Manoel de Medeiros s/n, Dois Irmãos, Recife, PE 52171-900.

${ }^{6}$ Docente da Unidade Acadêmica de Medicina Veterinária, Universidade Federal de Campina Grande (UFCG), Campus de Patos, Avenida Universitária s/n, Jatobá, Patos, PB 58708-110, Brasil.
} 
RESUMO.- Os lentiviros de pequenos ruminantes (LVPR) são responsáveis por enfermidades infecciosas e multissistêmicas causadas pelo Vírus da Artrite Encefalite Caprina (CAEV) e o Vírus da Maedi-Visna (MVV), e se apresentam sob as formas clínicas: articular, mamária, respiratória e nervosa. Desta forma esse trabalho objetivou determinar a ocorrência e avaliar os fatores de risco associados à infecção por LVPR no Estado de Sergipe, Brasil. Foram coletadas amostras sanguíneas de 1200 ovinos e 675 caprinos oriundos respectivamente de 60 e 41 propriedades localizadas em 25 municípios sergipanos no período de 2011 a 2014. Os diagnósticos dos LVPR foram determinados pela técnica sorológica de Imunodifusão em Gel Ágar (IDGA) usando o kit comercial da marca Biovetech ${ }^{\circledR}$. Os dados das variáveis associadas aos fatores de risco foram obtidos a partir de questionários aplicados aos proprietários dos rebanhos e analisados estatisticamente. As frequências absolutas e relativas foram determinadas por análise estatística descritiva e os fatores de risco por análise univariada das variáveis de interesse pelo Teste de Qui-quadrado de Pearson e Exato de Fisher, quando necessário, e em seguida submetidos à análise de regressão logística. Foi evidenciada uma soropositividade de 5,03\% (34/675) em caprinos e 1,50\% em ovinos com 26,82\% (11/41) e $28,33 \%(17 / 60)$ das propriedades apresentando ao menos um animal positivo respectivamente. $\mathrm{Na}$ análise dos fatores de risco, não foram observadas diferenças significantes para os ovinos, enquanto que, para os caprinos, rebanhos acima de 100 animais, que pastejam em áreas comuns com outros rebanhos, em uma distância $\leq 500$ metros entre as propriedades, que adotam medidas biotecnológicas da reprodução e não utilizam agulhas estéreis, são mais susceptíveis à infecção por LVPR. Sendo assim, conclui-se que, há a presença dos LVPR em rebanhos sergipanos, e mesmo que em baixas frequências faz-se necessário a implementação de medidas profiláticas devido a possibilidade de expansão e desenvolvimento da caprinocultura do estado, e o alto padrão genético da raça Santa Inês.

TERMOS DE INDEXAÇÃO: Fatores de risco, lentivírus, pequenos ruminantes, Sergipe, Vírus da Artrite Encefalite Caprina, caprinos, iunodifusão, gel de ágar, Maedi-Visna, ovinos, viroses.

\section{INTRODUÇÃO}

Por serem consideradas enfermidades virais específicas os lentivírus de caprinos e ovinos foram denominadas, respectivamente, de Artrite Encefalite Caprina (CAE) e Maedi-Visna (MV). No entanto após várias análises filogenéticas e sua transmissão interespecífica percebeu-se que esses vírus deviam ser classificados como um grupo heterogêneo e não como vírus estritamente relacionados à espécie, sendo então denominado de Lentivírus de Pequenos Ruminantes - LVPR (Castro et al. 1999, Germain \& Valas 2006).

Os LVPR são responsáveis por uma enfermidade cosmopolita, multissistêmica e infectocontagiosa de evolução lenta caracterizada por infecção persistente com disseminação vertical e horizontal, onde o manejo dos animais torna-se um fator de risco influente na extensão da soropositividade da doença no rebanho (Callado et al. 2001). Outra forma de disseminação do agente, é a partir da transmissão interespécie (Castro et al. 1999), ou ainda por via sêmen, como sugerido por Gregory et al. (2011) em pesquisas experimentais.
Geralmente os animais acometidos pelos LVPR são assintomáticos, no entanto na presença de sinais clínicos podem desenvolver artrite, com aumento de volume articular, em animais adultos, mastite endurativa aguda ou crônica, leucoencefalomielite aguda nos animais jovens e, em menor proporção, alterações respiratórias em caprinos, enquanto que nos ovinos as artrites são menos frequentes, no entanto apresenta quadros graves de comprometimento respiratório, seguido de emagrecimento progressivo, debilidade e em alguns casos a morte (Lara et al. 2013).

As lentiviroses de pequenos ruminantes são importantes não só pela característica de apresentar-se sob quatro formas clínicas, mas também pelos prejuízos econômicos que podem causar ao longo do tempo em rebanhos com animais soropositivos (Callado et al. 2001), como diminuição significativa na produção leiteira e no desempenho reprodutivo, acarretando aumento da taxa de descarte precoce, aquisição de animais de substituição negativos e desvalorização do rebanho (Bohland \& D'Angelino 2005, Lara 2006). Outro ponto econômico a considerar é a barreira sanitária imposta por alguns países para comercialização de produtos originados de rebanhos com animais soropositivos para os LVPR devido à notificação obrigatória de casos confirmados imposta pela Organização Mundial de Saúde Animal (OIE 2017).

Vários fatores de risco estão associados à infecção por LVPR, com destaque para o manejo sanitário implementado na formação de um rebanho, a aquisição de novos animais sem a realização de quarentena ou sorologia, o melhoramento genético e o sistema de criação adotado (Frota et al. 2005, Souza et al. 2012), que podem influenciar na epidemiologia da enfermidade, pois grandes concentrações, características de sistema intensivo ou semi-extensivo, favorecem a disseminação do agente (Silva \& Lima 2007, Souza et al. 2012).

Pode acometer pequenos ruminantes sem distinção de raça, sexo ou idade, apesar de, se observar geralmente que a maior ocorrência de animais soropositivos para os LVPR são os mais velhos, devido o tempo de soroconversão (Callado et al. 2001). Situações na qual o animal seja exposto a estresse, infecções bacterianas ou virais, acarreta numa queda imunológica podendo favorecer o desencadeamento dos sinais clínicos (Silva \& Lima 2007).

Inquéritos sorológicos acerca do CAEV e do MVV vêm sendo realizados durante anos em grande parte do país com exceção do Amapá, Roraima, Amazonas, Acre, Rondônia, Mato Grosso do Sul e Paraná, com frequências variando de 0\% a 50,6\% (Souza 2014). No Nordeste do Brasil, região com maior concentração de criações de pequenos ruminantes, os trabalhos mais recentes relatam uma ocorrência entre $0,66 \%$ e 8,16\% (Batista et al. 2004, Silva et al. 2005a, 2005b, Oliveira et al. 2006, Bandeira et al. 2009, Alves et al. 2011, Costa et al. 2011, Sampaio Júnior et al. 2011, Sardi et al. 2012, Lima et al. 2013, Mourão et al. 2016, Teixeira et al. 2016a, 2016b, Melo et al. 2016). Em Sergipe, estudos preliminares mostram que a ocorrência varia de $0,11 \%$ a $4,25 \%$ (Melo et al. 2003, Mendonça et al. 2013).

Com intuito de atualizar os dados existentes a respeito dos LVPR no Estado, esse trabalho objetivou determinar a ocorrência e avaliar os fatores de risco associados à infecção por LVPR no Estado de Sergipe. 


\section{MATERIAL E MÉTODOS}

O inquérito sorológico foi realizado em Sergipe (latitude $9^{\circ} 30^{\prime} 49^{\prime \prime}$ e $11^{\circ} 34^{\prime} 05^{\prime \prime}$ e longitude $36^{\circ} 23^{\prime} 40^{\prime \prime}$ e $38^{\circ} 15^{\prime} 00^{\prime \prime}$ ), estado brasileiro pertencente à região Nordeste que compreende uma área de $21.918,454$ km² $^{2}$ divididos em 75 municípios, distribuídos em três mesorregiões edafoclimáticas: leste, agreste e sertão. 0 clima é predominantemente tropical quente e úmido na faixa costeira, e à medida que se distancia do litoral, se caracteriza como tropical sub-úmido em uma faixa intermediária até o sertão o qual apresenta clima semiárido (IBGE 2015b, Mendonça et al. 2013, SIRHSE 2017). Possui um efetivo de 24.754 cabeças de caprinos e 205.151 de ovinos, sendo sua exploração produtiva complementar à bovinocultura (IBGE 2015a).

A escolha dos municípios e propriedades estudadas foi feita de acordo com a divisão do estado, facilidade de acesso e a disponibilidade dos caprinovinocultores em permitir as coletas. A maioria das criações de caprinos está no sertão, enquanto que os rebanhos ovinos no agreste do estado. A caprinocultura se caracteriza predominantemente por criações de subsistência, enquanto a ovinocultura tem reconhecimento nacional devido ao excelente padrão desenvolvido de animais puros e mestiços da raça Santa Inês (Seagri 2017a, 2017b).

Para definir o tamanho mínimo de 369 animais da amostragem a ser avaliada, foi aplicado o cálculo estatístico descrito por Thrusfield (2004), utilizando como parâmetros: a população de 24.754 caprinos e 205.151 ovinos (IBGE 2015a), intervalo de confiança de 95\%, percentual de margem de erro amostral de $5 \%$, e prevalência de $\pm 2,23 \%$, (Melo et al. 2003, Mendonça et al. 2013), a partir do uso do Software Win Episcope 2.0. Assim, foram coletadas de sete a vinte amostras por propriedade de animais selecionados aleatoriamente, entre machos e fêmeas, hígidos, de diferentes padrões zootécnicos (raças puras, mestiças e SRD) e idade superior a seis meses.

Para avaliação dos fatores de risco associados à infecção por LVPR foi aplicado, durante as coletas, um questionário epidemiológico composto de perguntas fechadas, relacionadas às características do rebanho com base na história pregressa, finalidade de criação, manejo sanitário, nutricional e reprodutivo, instalações e da caracterização do produtor.

As amostras sanguíneas de 675 caprinos e 1200 ovinos oriundos respectivamente de 41 e 60 propriedades de 25 municípios, foram coletadas no período de 2011 a 2012 (ovinos) e entre 2013 e 2014 (caprinos), por venopunção da jugular em tubo a vácuo (vacutainer ${ }^{\circledR}$ ), sem anticoagulante. Após centrifugação a $1600 \mathrm{~g}$ por 10 minutos, as alíquotas de soro obtidas foram acondicionadas em micro tubos e congeladas a $-20^{\circ} \mathrm{C}$ até o momento da análise.

O diagnóstico das lentiviroses foi realizado através do emprego da técnica de Imunodifusão em Gel Ágar (IDGA), seguindo o protocolo do fabricante (Biovetech ${ }^{\circledR}$ - Recife/PE). A leitura foi realizada após 48-72 horas sob incidência de luz em fundo escuro. Foram consideradas positivas as amostras que formaram linhas de precipitação entre o poço com o antígeno e o poço com a amostra teste. Todos os procedimentos diagnósticos foram realizados no Laboratório de Virologia do Departamento de Medicina Veterinária da Universidade Federal Rural de Pernambuco, em Recife.

Enquanto as frequências absolutas e relativas foram obtidas a partir de uma análise estatística descritiva, a avaliação dos fatores de risco associados à infecção pelos LVPR foi obtida através da análise univariada das variáveis de interesse pelo teste de Qui-quadrado de Pearson e, quando necessário, o Exato de Fisher, cujos dados extraídos foram aplicados numa análise de regressão logística considerando como variável dependente para a infecção por LVPR o resultado reagente ou não reagente observados no teste de IDGA. Dessa forma, foram consideradas apenas as variáveis cuja significância estatística foi $<0,20$, para que possíveis fatores de risco da pesquisa não fossem excluídos da análise (Hosmer \& Lemeshow 1989). Todo esse cálculo estatístico foi executado a partir do Programa Epilnfo 3.5.1.

Todo desenvolvimento do presente projeto de pesquisa foi realizado após aprovação da Comissão de Bioética da Faculdade Pio Décimo - Aracaju/SE, sob o protocolo de número 06/2011.

\section{RESULTADOS E DISCUSSÃO}

A ocorrência de pequenos ruminantes soropositivos para LVPR foi de 2,77\% (52/1875), sendo 5,03\% (34/675) dos caprinos e 1,5\% (18/1200) dos ovinos, com 26,82\% (11/41) e $28,33 \%$ (17/60) de propriedades com ao menos um animal soropositivo respectivamente (Quadro 1).

Valores semelhantes aos encontrados nesse estudo e associados à infecção pelo CAEV e MVV foram descritos em outros trabalhos no Nordeste (Oliveira et al. 2006, Bandeira et al. 2009, Alves et al. 2011, Costa et al. 2011, Sampaio Júnior et al. 2011, Sardi et al. 2012, Melo et al. 2016, Mourão et al. 2016, Teixeira et al. 2016a, 2016b). Essas variações das ocorrências podem ser resultado do número de animais analisados nesses estudos, bem como as características raciais, uma vez que rebanhos com animais de raças nativas, mestiças e sem raça definida (SRD), podem apresentar menores riscos de contrair a infecção pelos LVPR (Batista et al. 2004, Bandeira et al. 2009, Alves et al. 2011). O manejo sanitário adotado em cada propriedade também pode influenciar na soropositividade encontrada (Callado et al. 2001), bem como o sistema de criação adotado, uma vez que animais criados em sistema extensivo tem menos chance de se infectar com o vírus pelo menor contato entre os animais, dificultando assim a transmissão horizontal (Souza et a. 2012).

Quando se compara as ocorrências associadas ao LVPR obtidas nesse estudo, com as de 4,25\% (2/47) associada ao CAEV e $0 \%(0 / 107)$ ao MVV relatado por Melo et al. (2003) e as de 0,11\% (1/941) associada ao MVV relatada por Mendonça et al. (2013) ambos em Sergipe, observa-se que não houve aumento significativo da infecção no Estado.

O método diagnóstico empregado também poderá influenciar na contagem final de animais soropositivos num rebanho. Apesar da técnica de IDGA ser recomendada pela OIE como teste de referência para detecção de anticorpos para os LVPR, por seu baixo custo e simplicidade na execução, esse teste apresenta baixa sensibilidade o que pode levar a resultados falso-negativos. Sardi et al. (2012) observou que de 755 amostras negativas na IDGA escolhidas aleatoriamente para diagnóstico pela técnica de ELISA Indireto, cinco animais revelaram-se positivos, demonstrando mais sensibilidade do ELISA na detecção de anticorpos de LVPR. Isso porque o ELISA detecta anticorpos precocemente a infecção (Torres et al. 2009).

Para os fatores de risco associados à infecção em ovinos (Quadro 2) não foram observadas significância estatística na análise de regressão logística multivariada, o que evidencia ser devido as criações, em sua maioria, de animais raciados onde as práticas de manejo são mais tecnificadas. Nota-se também que apesar da presença de caprinos na mesma propriedade que rebanhos ovinos, o que os expõe a transmissão viral interespécies, o sistema de criação predominante foi o semiextensivo seguido do sistema extensivo, o qual propicia uma 
Quadro 1. Distribuição e ocorrência de pequenos ruminantes soropositivos a LVPR em 25 municípios de três Mesorregiões do estado de Sergipe

\begin{tabular}{|c|c|c|c|c|c|c|}
\hline \multirow[b]{2}{*}{ Município } & \multicolumn{2}{|c|}{ Ovinos (\%) } & \multicolumn{2}{|c|}{ Caprinos (\%) } & \multicolumn{2}{|c|}{ Pequenos ruminantes (\%) } \\
\hline & $\begin{array}{c}\text { Positivo/ } \\
\text { Propriedades }\end{array}$ & $\begin{array}{c}\text { Positivo/ } \\
\text { Total } \\
\end{array}$ & $\begin{array}{c}\text { Positivo/ } \\
\text { Propriedades }\end{array}$ & $\begin{array}{c}\text { Positivo/ } \\
\text { Total } \\
\end{array}$ & $\begin{array}{c}\text { Positivo/ } \\
\text { Propriedades }\end{array}$ & $\begin{array}{c}\text { Positivo/ } \\
\text { Total } \\
\end{array}$ \\
\hline Aracaju & $0 / 1$ & $0 / 20$ & $0 / 3$ & $0 / 50$ & $0 / 4$ & $0 / 70$ \\
\hline Arauá & $0 / 3$ & $0 / 60$ & - & - & $0 / 3$ & $0 / 60$ \\
\hline Boquim & $0 / 1$ & $0 / 20$ & - & - & $0 / 1$ & $0 / 20$ \\
\hline Divina Pastora & $1 / 3(33,33)$ & $1 / 60(1,66)$ & - & - & $1 / 3(33,33)$ & $1 / 60(1,75)$ \\
\hline Estância & $3 / 4(75)$ & $3 / 80(3,75)$ & $1 / 1(100)$ & $3 / 20(15)$ & $4 / 5(80)$ & $6 / 100(6)$ \\
\hline Itaporanga D’Ajuda & $2 / 5(40)$ & $2 / 100(2)$ & $1 / 1(100)$ & $2 / 20(10)$ & $3 / 6(50)$ & $4 / 120(3,33)$ \\
\hline Maruim & $0 / 2$ & $0 / 40$ & - & - & $0 / 2$ & $0 / 40$ \\
\hline Nossa Senhora do Socorro & $0 / 1$ & $0 / 20$ & $0 / 1$ & $0 / 18$ & $0 / 2$ & $0 / 38$ \\
\hline Salgado & $2 / 3(66,66)$ & $2 / 60(3,33)$ & $0 / 2$ & $0 / 30$ & $2 / 5(40)$ & $2 / 90(2,22)$ \\
\hline São Cristóvão & $2 / 2(100)$ & $3 / 40(7,50)$ & $0 / 1$ & $0 / 20$ & $2 / 3(66,66)$ & $3 / 60(5)$ \\
\hline Itabaianinha & $2 / 9(22,22)$ & $2 / 180(1,11)$ & - & - & $2 / 9(22,22)$ & $2 / 180(1,11)$ \\
\hline Neópolis & - & - & $1 / 1(100)$ & $3 / 20(15)$ & $1 / 1(100)$ & $3 / 20(15)$ \\
\hline Região Leste & $12 / 34(35,29)$ & $13 / 680(1,91)$ & $3 / 10(30)$ & $8 / 178(4,49)$ & $15 / 44(34,09)$ & $21 / 858(2,44)$ \\
\hline Itabaiana & - & - & $0 / 1$ & $0 / 20$ & $0 / 1$ & $0 / 20$ \\
\hline Lagarto & $2 / 6(33,33)$ & $2 / 120(1,66)$ & $0 / 1$ & $0 / 20$ & $2 / 7(28,57)$ & $2 / 140(1,42)$ \\
\hline Macambira & - & - & $1 / 3(33,33)$ & $1 / 42(2,38)$ & $1 / 3(33,33)$ & $1 / 42(2,38)$ \\
\hline Cumbe & $0 / 1$ & $0 / 20$ & - & - & $0 / 1$ & $0 / 20$ \\
\hline Nossa Senhora das Dores & $0 / 4$ & $0 / 80$ & - & - & $0 / 4$ & $0 / 80$ \\
\hline Poço Verde & - & - & $3 / 11(27,27)$ & $8 / 153(5,22)$ & $3 / 11(27,27)$ & $8 / 153(5,22)$ \\
\hline Simão Dias & $2 / 3(66,66)$ & $2 / 60(3,33)$ & - & - & $2 / 3(66,66)$ & $2 / 60(3,33)$ \\
\hline Região Agreste & $4 / 14(28,57)$ & $4 / 280(1,42)$ & $4 / 16(25)$ & $9 / 235(3,82)$ & $8 / 30(26,66)$ & $13 / 497(2,61)$ \\
\hline Canindé de São Francisco & $0 / 4$ & $0 / 80$ & $2 / 6(33,3)$ & $3 / 120(2,5)$ & $2 / 10(20)$ & $3 / 200(1,5)$ \\
\hline Feira Nova & $1 / 2(50)$ & $1 / 40(2,50)$ & - & - & $1 / 2(50)$ & $1 / 40(2,5)$ \\
\hline Itabi & $0 / 2$ & $0 / 40$ & - & - & $1 / 2(50)$ & $0 / 40$ \\
\hline Nossa Senhora da Glória & $0 / 4$ & $0 / 80$ & $1 / 6(16,7)$ & $2 / 92(2,17)$ & $1 / 10(10)$ & $2 / 172(1,16)$ \\
\hline Pedra Mole & - & - & $0 / 1$ & $0 / 11$ & $0 / 1$ & $0 / 11$ \\
\hline Pinhão & - & - & $1 / 2(50)$ & $12 / 39(30,76)$ & $1 / 2(50)$ & $12 / 39(30,76)$ \\
\hline Região Sertão & $1 / 12(8,33)$ & $1 / 240(0,41)$ & $4 / 15(26,66)$ & $17 / 262(6,48)$ & $6 / 27(22,22)$ & $18 / 502(3,58)$ \\
\hline TOTAL & $17 / 60(28,33)$ & $18 / 1200(1,5)$ & $11 / 41(26,82)$ & $34 / 675(5,03)$ & $28 / 101(27,72)$ & $52 / 1875(2,77)$ \\
\hline
\end{tabular}

Quadro 2. Fatores de risco associados à infecção de LVPR em rebanhos ovinos oriundos de propriedades rurais do estado de Sergipe, por variável analisada e total

\begin{tabular}{lccc}
\hline \multicolumn{1}{c}{ Variável } & $\mathrm{N}$ & $\begin{array}{c}\text { IDGA } \\
\text { reagente (\%) }\end{array}$ & Valor de $\mathrm{p}$ \\
\hline $\begin{array}{l}\text { Microrregião } \\
\text { Leste }\end{array}$ & 680 & $13(1,91)$ & 0,259 \\
Agreste & 280 & $4(1,42)$ & $1(0,41)$ \\
$\quad$ Sertão & 240 & & 0,389 \\
Sexo & & & $1(1,90)$ \\
$\quad$ Macho & 210 & $14(1,41)$ & 0,557 \\
Fêmea & 990 & - & $17(1,59)$ \\
Raça & 72 & $1(1,53)$
\end{tabular}


Quadro 2. Continuação...

\begin{tabular}{|c|c|c|c|}
\hline Variável & $\mathrm{N}$ & $\begin{array}{c}\text { IDGA } \\
\text { reagente (\%) }\end{array}$ & Valor de $\mathrm{p}$ \\
\hline \multicolumn{4}{|l|}{ Regime de Criação } \\
\hline Extensivo & 500 & $5(1)$ & 0,298 \\
\hline Intensivo & 60 & $2(3,33)$ & \\
\hline Semi-extensivo & 640 & $11(1,71)$ & \\
\hline \multicolumn{4}{|l|}{ Presença de caprino } \\
\hline Não & 780 & $14(1,79)$ & 0,186 \\
\hline Sim & 420 & $4(0,95)$ & \\
\hline \multicolumn{4}{|c|}{ Contato entre animais saudáveis e enfermos } \\
\hline Não & 680 & $14(2,05)$ & 0,053 \\
\hline Sim & 520 & $4(0,76)$ & \\
\hline \multicolumn{4}{|l|}{ Uso de agulhas estéreis } \\
\hline Não & 660 & $9(1,36)$ & 0,421 \\
\hline Sim & 540 & $9(1,66)$ & \\
\hline \multicolumn{4}{|c|}{ Fornecimento de colostro } \\
\hline Não & 20 & - & 0,737 \\
\hline Sim & 1180 & $18(1,52)$ & \\
\hline \multicolumn{4}{|l|}{ Desinfeta instalações } \\
\hline Não & 620 & $7(1,12)$ & 0,196 \\
\hline Sim & 580 & $11(1,89)$ & \\
\hline
\end{tabular}

diminuição do contato entre os animais e maior área para pastejo, os distanciando das fontes de infecção (Pérez et al. 2010).

$\mathrm{Na}$ análise univariada baseada em questionários epidemiológicos, aplicados durante as coletas evidenciou-se que o padrão racial, distância entre propriedades, pastejo com outros criadores, uso de biotecnologias da reprodução, contato entre animais saudáveis e enfermos, e a utilização de agulhas estéreis foram estatisticamente significativas com base no valor de $\mathrm{p}(\mathrm{p}<0,05)$ associado ao LVPR em caprinos (Quadro 3).

No Quadro 4 observa-se que na análise de regressão logística multivariada para os fatores de risco associados ao LVPR em caprinos, propriedades cujo rebanho ultrapassa 100 animais e pastejam em áreas comuns a outros rebanhos numa distância igual ou inferior a 500 metros, que adotam práticas biotecnológicas mais intensivistas, e que durante essas práticas não fazem uso de agulhas estéreis são mais susceptíveis a infecção por LVPR.

O tamanho do rebanho associado com pastejo comunal e a proximidade entre as instalações dos animais teve valor significativo sobre o risco aumentado de infecção por LVPR (Silva \& Lima 2007, Junkuszew et al. 2016). A concentração de um grande número de animais, de diferentes espécies em locais de espaço limitado, viabiliza o contato direto com secreções e/ou excreções ricas em células do sistema monocítico-fagocitário contendo carga viral, disseminando assim de forma horizontal o LVPR. A densidade populacional em locais mais fechados também expõe o animal a estresse, o que pode levar a diminuição da imunidade e consequente suscetibilidade a infecções. Um agravante para essas condições sugerido por Pérez et al. (2010) é a forma de manejo de como os rebanhos são geridos, pois quanto mais animais e menos tecnificado a criação, maior a probabilidade de descontrole no que diz respeito ao período de parição, à alimentação, instalações, estratégias de abate e substituições dos animais. Quando se tem um rebanho grande com pastejo comunal e sem controle é passível de mais duas possibilidades, a primeira diz respeito ao não controle de período gestacional, ou seja, os animais parem sem assistência entre os animais do rebanho, o outro ponto é o controle regrado da parição o que proporciona o aleitamento materno de outras fêmeas, favorecendo a transmissão vertical do LVPR.

As práticas de biotecnologias da reprodução associadas ou não ao uso de agulhas não estéreis, são epidemiologicamente importantes para transmissão dos LVPR (Blacklaws et al. 2004, Silva \& Lima 2007). Animais que são mais manejados, expostos a processos como vacinação, vermifugação, marcação com brinco, tatuador, ou quaisquer outras práticas com uso de agulhas ou perfurocortantes não esterilizados, suscetibiliza a infecção. Sobre as práticas biotecnológicas, como a transferência de embriões e inseminação artificial podem transmitir o LVPR, uma vez que já foi comprovada a presença de DNA-viral no sêmen, ovócito e fluido uterino de caprinos (Gregory et al. 2011, Cavalcante et al. 2013).

Dessa forma vale ressaltar a importância da implementação de medidas de controle como: segregar animais soropositivos do rebanho e descarta-los gradativamente, em casos de fêmeas prenhes reagentes separá-la da cria ao nascimento e não oferecer colostro ou leite da mesma para outros animais, adotar técnicas sorológicas para acompanhamento da infecção no rebanho uma vez que pode ocorrer soroconversão tardia (Souza et al. 2015). Quanto às práticas sanitárias, a adoção de limpeza e desinfecção com detergentes ou formol pode inativar o vírus, e o uso de agulhas estéreis por animal durante 
Quadro 3. Fatores de risco associados à infecção ao Vírus da Artrite Encefalite Caprina (VAEC) em rebanhos caprinos oriundos de propriedades rurais do estado de Sergipe, por variável analisada e total

\begin{tabular}{|c|c|c|c|}
\hline Variável & $\mathrm{N}$ & $\begin{array}{c}\text { IDGA } \\
\text { Reagente (\%) }\end{array}$ & Valor de $\mathrm{p}$ \\
\hline \multicolumn{4}{|l|}{ Microrregião } \\
\hline Leste & 178 & $8(4,49)$ & 0,371 \\
\hline Agreste & 235 & $9(3,82)$ & \\
\hline Sertão & 262 & $17(6,48)$ & \\
\hline \multicolumn{4}{|l|}{ Sexo } \\
\hline Fêmea & 566 & $30(5,3)$ & 0,332 \\
\hline Macho & 109 & $4(3,66)$ & \\
\hline \multicolumn{4}{|l|}{ Raça } \\
\hline Anglo Nubiana & 60 & $2(3,33)$ & 0,000 \\
\hline Boer & 54 & - & \\
\hline Parda Alpina & 16 & $4(25)$ & \\
\hline Saanen & 216 & $16(7,40)$ & \\
\hline SRD & 321 & $12(3,73)$ & \\
\hline Toggenburg & 8 & - & \\
\hline \multicolumn{4}{|l|}{ Finalidade da criação } \\
\hline Corte & 298 & $9(3,02)$ & 0,023 \\
\hline Leite & 377 & $25(6,63)$ & \\
\hline \multicolumn{4}{|l|}{ Total de caprinos } \\
\hline Até 50 & 248 & $6(2,41)$ & 0,051 \\
\hline Entre 51 e 100 & 59 & $3(5,08)$ & \\
\hline Acima de 100 & 368 & $25(6,79)$ & \\
\hline \multicolumn{4}{|l|}{ Presença de ovinos } \\
\hline Não & 293 & $21(7,16)$ & 0,021 \\
\hline Sim & 382 & $13(3,40)$ & \\
\hline \multicolumn{4}{|l|}{ Regime de Criação } \\
\hline Extensivo & 114 & $1(0,87)$ & 0,021 \\
\hline Intensivo & 108 & $3(2,77)$ & \\
\hline Semi-extensivo & 452 & $30(6,63)$ & \\
\hline \multicolumn{4}{|c|}{ Distância entre propriedade } \\
\hline$>500$ metros & 400 & $10(2,5)$ & 0,000 \\
\hline$\leq 500$ metros & 275 & $24(8,72)$ & \\
\hline \multicolumn{4}{|c|}{ Pastejo com outros criadores } \\
\hline Não & 533 & $18(3,37)$ & 0,000 \\
\hline Sim & 142 & $16(11,26)$ & \\
\hline \multicolumn{4}{|c|}{ Biotecnologias da reprodução } \\
\hline Não & 492 & $15(3,04)$ & 0,000 \\
\hline Sim & 183 & $19(10,38)$ & \\
\hline \multicolumn{4}{|c|}{ Contato entre animais saudáveis e enfermos } \\
\hline Não & 261 & $32(12,26)$ & 0,000 \\
\hline Sim & 414 & $2(0,48)$ & \\
\hline \multicolumn{4}{|l|}{ Uso de agulhas estéreis } \\
\hline Não & 274 & $26(9,48)$ & 0,000 \\
\hline Sim & 401 & $8(1,99)$ & \\
\hline \multicolumn{4}{|l|}{ Desinfeta instalações } \\
\hline Não & 160 & $4(2,5)$ & 0,063 \\
\hline Sim & 515 & $30(5,82)$ & \\
\hline
\end{tabular}

Quadro 4. Análise de regressão logística dos fatores de risco associados à infecção pelo Vírus da Artrite Encefalite Caprina (VAEC) em caprinos oriundos de propriedades rurais do estado de Sergipe

\begin{tabular}{lccc}
\hline \multicolumn{1}{c}{ Variáveis } & Valor de $\mathrm{p}$ & OR & IC 95\% \\
\hline Acima de 100 animais & 0,003 & 4,02 & $1,58-10,26$ \\
Distância $\leq 500$ metros & 0,000 & 4,08 & $1,82-9,10$ \\
Pastejo com outros criadores & 0,002 & 4,08 & $1,93-8,63$ \\
Biotecnologia da reprodução & 0,009 & 3,74 & $1,39-10,06$ \\
Não utilizar agulhas estéreis & 0,004 & 3,38 & $1,47-7,75$
\end{tabular}


qualquer procedimento diminui a chance de transmissão horizontal (Silva \& Lima 2007).

\section{CONCLUSÃO}

Com base nos resultados obtidos pode-se afirmar que os LVPR estão disseminados nos rebanhos caprinos e ovinos sergipanos, em uma baixa ocorrência. 0 que demonstra a necessidade de implementação de medidas profiláticas, devido, o potencial de expansão e desenvolvimento da caprinocultura no estado, e o alto padrão genético da raça Santa Inês.

Agradecimentos.- Ao Grupo de Iniciação Científica e Extensão em Buiatria (GICEB) da Faculdade Pio Décimo de Aracaju/SE pela execução do Projeto.

\section{REFERÊNCIAS}

Alves F.S.F., Santiago L.B., Lima A.M.C., Farias D.A., Pinheiro R.R. \& Cavalcante A.C.R. 2011. Inquérito sorológico da infecção pelos lentivírus de pequenos ruminantes em rebanhos de caprinos e ovinos de quatro mesorregiões do estado do Ceará, Brasil. Revta Educ. Cont. Med. Vet. Zootec. CRMV-SP 9(3):40

Bandeira D.A., Castro R.S., Azevedo E.O., Melo L.S.S. \& Melo C.B. 2009. Seroprevalence of caprine arthritis-encephalitis vírus in goats in the Cariri region, Paraíba state, Brazil. Vet. J. 180(3):399-401. http://dx.doi. org/10.1016/j.tvjl.2008.02.007. PMid:18675568.

Batista M.C.S., Castro R.S., Carvalho F.A.A., Cruz M.S.P., Silva S.M.M.S., Rego E.W. \& Lopes J.B. 2004. Anticorpos anti-lentivírus de pequenos ruminantes em caprinos do estado do Piauí. Ciênc. Vet. Trópicos 76(2/3):75-81.

Blacklaws B.A., Berriatua E., Torsteinsdottir S., Watt N.J., De Andres D., Klein D. \& Harkiss G.D. 2004. Transmission of small rumiant lentiviruses. Vet. Microbiol. 101(3):199-208. http://dx.doi.org/10.1016/j.vetmic.2004.04.006. PMid:15223124.

Bohland E. \& D’Angelino J.L. 2005. Artrite encefalite caprina: avaliação dos aspectos produtivos e reprodutivos de animais infectados e não infectados. Braz. J. Vet. Res. Anim. Sci. 42(2):81-88. http://dx.doi.org/10.11606/ issn.1678-4456.bjvras.2005.26437.

Callado A.K.C., Castro R.S. \& Teixeira M.F.S. 2001. Lentivírus de pequenos ruminantes (CAEV e Maedi-Visna): revisão e perspectivas. Pesq. Vet. Bras. 21(3):87-97. http://dx.doi.org/10.1590/S0100-736X2001000300001.

Castro R.S., Greenland T., Leite R.C., Gouveia A.M.J., Mornex J.-F. \& Cordier G. 1999. Conserved sequence motifs involving the tat frame of Brazilian caprine lentiviruses indicate affiliations to both caprine arthritis-encephalitis vírus and visna-maedi vírus. J. Gen. Virol. 80(Pt 7):1583-1589. http://dx.doi. org/10.1099/0022-1317-80-7-1583. PMid:10423125.

Cavalcante F.R.A., Andrioli A., Pinheiro R.R., Souza K.C., Veras A.K.A., Lopes T.A., Souza S.D. \& Silva P.A.F. 2013. Detecção do vírus da artrite encefalite caprina por nested PCR e nested RT-PCR em ovócitos e fluido uterino. Arqs Inst. Biológico, São Paulo, 80(4):381-386.

Costa A.B.B., Emery B.D., Araújo M.V., Teles J.A.A. \& Abreu S.R.O. 2011. Inquérito soroepidemiológico de lentivírus de pequenos ruminantes no município de Delmiro Gouveia, Alagoas, Brasil. Revta Semente 6(6):229-239.

Frota M.N.L., Silva J.B.A., Araújo S.A.C. \& Teixeira M.F.S. 2005. Artrite encefalite caprina em cabritos de rebanhos com programa de controle no Estado do Ceará. Arqs Inst. Biológico, São Paulo, 72:147-152.

Germain K. \& Valas S. 2006. Distribution and heterogeneity of small ruminant lentivírus envelope subtypes in naturally infected Frech sheep. Virus Res. $120(1 / 2): 156-162$. http://dx.doi.org/10.1016/j.virusres.2006.03.002. PMid:16616391.

Gregory L., Lara M.C.C.S.H., Hasegawa M.Y., Castro R.S., Rodrigues J.N.M., Araújo J., Keller L.W., Silva L.K.F. \& Durigon E.L. 2011. Detecção do vírus da artrite encefalite caprina no sêmen através das técnicas de PCR e Nested-PCR. Arqs Inst. Biológico, São Paulo, 78(4):599-603.
Hosmer D. \& Lemeshow S. 1989. Applied Logistic Regression. John Wiley and Sons Inc., New York. 307p.

IBGE 2015a. Sergipe: pecuária 2015. Instituto Brasileiro de Geografia e Estatística. Disponível em <http://www.ibge.gov.br/estadosat/temas. php?sigla=se\&tema=pecuaria2015> Acesso em 10 jan. 2017.

IBGE 2015b. Estados: Sergipe. Instituto Brasileiro de Geografia e Estatística. Disponível em <http://www.ibge.gov.br/estadosat/perfil.php?sigla=se> Acesso em 10 jan. 2017.

Junkuszew A., Dudko P., Bojar W., Olech M., Osiński Z., Gruszecki T.M., Kania M.G., Kuźmak J. \& Czerski G. 2016. Risk factors associated with small ruminant lentivirus infection in eastern Poland sheep flocks. Prev. Vet. Med. 127:44-49. http://dx.doi.org/10.1016/j.prevetmed.2016.03.011. PMid:27094139.

Lara M.C.C.S.H. 2006. Artrite-encefalite dos caprinos (Palestra). Arqs Inst. Biológico, São Paulo, 68(1/2):21-23.

Lara M.C.C.S.H., Villalobos E.M.C., Cunha E.M.S., Chiebao D., Gabriel F.H., Paulin L., Castro V., Nassar A.F.C., Piatti R., Okuda L., Romaldini A.H.C.N., Federsoni I.S.P., Lucchese Filho A., Felício A.L.A., Pino F.A.P., Azevedo S.S. \& Cardoso M.V. 2013. Inquérito sorológico de lentiviroses de pequenos ruminantes (Maedi-Visna e artrite encefalite caprina) no estado de São Paulo. Braz. J. Vet. Res. Anim. Sci. 50(1):18-25. http://dx.doi.org/10.11606/ issn.2318-3659.v50i1p18-25.

Lima C.C.V., Costa J.N., Souza T.S., Martinez P., Costa Neto A.O., Anunciação A.V.M., Almeida M.G.A.R., Araújo B.R. \& Pinheiro R.R. 2013. Inquérito soroepidemiológico do lentivírus caprino e perfil das criações de caprinos na região do Baixo Médio São Francisco (BA). Arqs Inst. Biológico, São Paulo, 80(3):288-296.

Melo C.B., Castro R.S. \& Oliveira A.A. 2003. Estudo preliminar sobre a infecção por lentivírus de pequenos ruminantes em ovinos e caprinos de Sergipe. Anais Congresso Latinoamericano de Buiatria, Salvador, BA, p.47-48.

Melo E.X., Almeida E.C., Mendonça K.M.N., Nascimento A.S., Silva J.C.R., Marvulo M.F.V., Rizzo H. \& Castro R.S. 2016. Soroprevalência da infecção por lentivírus de pequenos ruminantes em abatedouros do estado de Pernambuco, Brasil. Arqs Inst. Biológico, São Paulo, 83:1-4.

Mendonça C.E.D., Barros S.L.B., Mendonça M.A.D., Guimarães V.A.A. \& Pinheiro R.R. 2013. Ocorrência de anticorpos contra o vírus Maedi-Visna em ovinos Santa Inês, no estado de Sergipe, Brasil. Arqs Inst. Biológico, São Paulo, 80(3):346-351.

Mourão P.A., Lamark L., Oliveira M.M.M. \& Silva A.L.A. 2016. Estudo epidemiológico das lentiviroses de pequenos ruminantes na mesorregião do oeste Maranhense, Brasil. Publ. Med. Vet. Zootec. 10(7):550-555.

OIE 2017. Listed diseases, infection and infestations in force in 2017. Organização Mundial de Saúde Animal. Disponível em <http://www.oie. int/en/animal-health-in-the-world/oie-listed-diseases-2017/> Acesso em 28 jan. 2017.

Oliveira M.M.M., Castro R.S., Carneiro K.L., Nascimento S.A., Callado A.K.C., Alencar C.S.A. \& Costa L.S.P. 2006. Anticorpos contra lentivírus de pequenos ruminantes em caprinos e ovinos em abatedouros do estado de Pernambuco. Arq. Bras. Med. Vet. Zootec. 58(5):947-949. http://dx.doi.org/10.1590/ S0102-09352006000500035.

Pérez M., Biescas E., De Andrés X., Leginagoikoa I., Salazar E., Berriatua E., Reina R., Bolea R., De Andrés D., Juste R.A., Cancer J., Gracia J., Amorena B., Badiola J.J. \& Luján L. 2010. Visna/maedi vírus serology in sheep: survey, risk factors and impemention of a successful control programme in Aragón, Spain. Vet. J. 186(2):221-225. http://dx.doi.org/10.1016/j. tvjl.2009.07.031. PMid:19747864.

Sampaio Júnior A., Batista M.C.S., Cruz M.S.P., Silva R.A.B., Bona Nascimento C. \& Werneck G.L. 2011. Prevalência da infecção por lentivírus de pequenos ruminantes em caprinos em Teresina, Piauí. Arq. Bras. Med. Vet. Zootec. 63(3):757-760. http://dx.doi.org/10.1590/S0102-09352011000300032. 
Sardi S.I., Sena G.S.R., Campos G.S., Santos G.R., Maia Neto A.L. \& Ávila L.N. 2012. Ocorrência de lentivírus de pequenos ruminantes no semiárido baiano e perfil da caprino/ovinocultura na região. Ciênc. Anim. Bras. 13(4):494-503. http://dx.doi.org/10.5216/cab.v13i4.17429.

SEAGRI 2017a. Caprinocultura. Secretaria de Estado da Agricultura, Desenvolvimento Agrário e da Pesca. Disponível em <http://www.seagri. se.gov.br/indicadores/16/caprinocultura> Acesso em 10 jan. 2017.

SEAGRI 2017b. Ovinocultura. Secretaria de Estado da Agricultura, Desenvolvimento Agrário e da Pesca. Disponível em <http://www.seagri. se.gov.br/indicadores/17/ovinocultura> Acesso em 10 jan. 2017.

Silva J.B.A. \& Lima P.M. 2007. Lentivírus de pequenos ruminantes: caracterização etiológica, infectividade, controle, prevenção e diagnóstico. Acta Veterinaria Brasilica 1(4):111-117.

Silva J.S., Castro R.S., Melo C.B. \& Feijó F.M.C. 2005a. Infecção pelo vírus da artrite encefalite caprina no Rio Grande do Norte. Arq. Bras. Med. Vet. Zootec. 57(6):726-731. http://dx.doi.org/10.1590/S0102-09352005000600003.

Silva J.B.A., Neto C.F., Dantas M.I.C., Barreto Júnior R.A., Souza C.H., Dias R.V.C. \& Teixeira M.F.S. 2005b. Presença da artrite encefalite caprina em rebanhos caprinos da microrregião de Angicos no estado do Rio Grande do Norte. Ciência Animal 15(1):53-56.

SIRHSE 2017. Clima. Sistema de Informação sobre Recursos Hídricos. Disponível em <http://sirhse.semarh.se.gov.br/sirhse/index.php/macroplanejamento/ bacias_hidrograficas/estadoClima/estado> Acesso em 10 jan. 2017.

Souza T.S. 2014. Transmissão interespécies de lentivírus de caprinos para ovinos. Tese de Doutorado, Escola de Medicina Veterinária e Zootecnia, Universidade
Federal da Bahia, Salvador. 123p. Disponível em <http://www.mevtropical. ufba.br/arquivos/teses/2011/souzats2.pdf> Acesso em 1 abr. 2017.

Souza T.S., Pinheiro R.R., Lima C.C.V. \& Costa J.N. 2012. Transmissão interespécie dos lentivírus de pequenos ruminantes: revisão e desafios. Acta Veterinaria Brasilica 6(1):23-34.

Souza T.S., Pinheiro R.R., Costa J.N., Lima C.C.V., Andrioli A., Azevedo D.A.A., Santos V.W.S., Araújo J.F., Souza A.L.M., Pinheiro D.N.S., Fernandes F.M.C. \& Costa Neto A.O. 2015. Interspecific transmission of small ruminant lentiviruses from goats to sheep. Braz. J. Microbiol. 46(3):867-874. http:// dx.doi.org/10.1590/S1517-838246320140402. PMid:26413072.

Teixeira W.C., Azevedo E.O., Nascimento S.A., Mavulo M.F.V., Rizzo H., Silva J.C.R. \& Castro R.S. 2016a. Soroprevalência de Maedi-visna em rebanhos ovinos do estado do Maranhão, Brasil. Revta Bras. Ciênc. Vet. 23(1/2):42-47.

Teixeira W.C., Santos H.P., Veschi J.L.A., Nascimento S.A., Silva J.C.R., Marvulo M.F.V., Rizzo H. \& Castro R.S. 2016b. Prevalência da infecção pelo vírus da Artrite Encefalite Caprina em rebanhos do estado do Maranhão, Brasil. Revta Bras. Med. Vet. 38(1):1-6.

Thrusfield M. 2004. Epidemiologia Veterinária. $2^{\mathrm{a}}$ ed. Roca Press, São Paulo. $556 \mathrm{p}$.

Torres J.A., Campos G.S., Freitas M.M., Brandão C.F.L. \& Sardi S.I. 2009. Produção de antígeno viral para o sorodiagnóstico da Artrite encefalite caprina utilizando um teste imunoenzimatico (ELISA). Revta Ciênc. Méd. Biol. 8(2):107-114. 